\title{
La Sociedad del Conocimiento para el Desarrollo Humano desde la perspectiva de distintos modelos educativos
}

\section{The Knowledge Society for Human Development from the perspective of different educational models}

SALGADO-VARGAS, Christian Karel†*, ESCOBAR-ELIGIA, Francisco y ROMERO-ROMERO, Araceli

Centro de Investigaciones Multidisciplinarias en Educación (CIME). Universidad Autónoma del Estado de México

ID $1^{\text {er }}$ Autor: Christian Karel, Salgado-Vargas / ORC ID: 0000-0003-3311-9131, CVU CONACYT ID: 809174

ID $1^{\text {er }}$ Coautor: Francisco, Escobar-Eligia / ORC ID: 0000-0002-1233-2905, CVU CONACYT ID: 809171

ID $2^{\text {do }}$ Coautor: Araceli, Romero-Romero / ORC ID: 0000-0002-0328-0525, Researcher ID Thomson: O-4888-2015, CVU CONACYT ID: 392910

\section{Resumen}

Al establecer las bases conceptuales sobre el proceso evolutivo de la Universidad y el análisis de los modelos educativos en diferentes regiones del mundo como el medieval, Francés, Inglés, Norteamericano, Alemán y el Modelo Universitario en México, la intención de esto es identificar el tipo de prácticas que ayudan a continuar en vigor, adaptándonos a las necesidades actuales en términos de administración y métodos de enseñanza que responden a la reflexión en la Universidad del siglo XXI y determinen las bases para entender la evolución social de la Universidad y de las sociedades del conocimiento que se está gestando en un mundo donde ya no hay fronteras que sin duda impactan en el desarrollo humano y social.

\section{Educación Universitaria, Modelos} educativos, Antecedente

\begin{abstract}
Establishes the conceptual bases about the evolutionary process of the University and the analysis of the educational models in different regions of the world such as Medieval, French, English, North American, German and the University Model in Mexico, the intention of this is identify the kind of practices that help to continue in force, adapting to the current needs in terms of administration and teaching methods that respond to the reflection on the 21 st century university and establish the bases for understanding the social evolution of the university and the knowledge societies that is gestating in a world where there are no longer borders that undoubtedly impact on human and social development.
\end{abstract}

University Education, Models Teaching, Background

Citación: SALGADO-VARGAS, Christian Karel, ESCOBAR-ELIGIA, Francisco y ROMERO-ROMERO, Araceli. La Sociedad del Conocimiento para el Desarrollo Humano desde la perspectiva de distintos modelos educativos. Revista de Ciencias de la Educación. 2019. 3-8: 1-15

\footnotetext{
* Correspondencia del Autor (correo electrónico: karelitasalgado@gmail.com)

$\dagger$ Investigador contribuyendo como primer autor.
} 


\section{Introducción}

El proceso evolutivo ha permitido la comparación de hechos históricos que han impactado en el desarrollo humano a partir de análisis a acontecimientos y hechos fenómenos y supuestos históricos se explica para comprender la evolución social. Por ello es importante conocer los antecedentes de la Universidad a través de un recorrido histórico de la universidad a través del tiempo. El cual permitirá conocer aportes importantes en el surgimiento de la Universidad.

El termino universidad no fue dado por un solo acontecimiento histórico si no que es el resultado de diferentes sucesos que permitieron el surgimiento y el desarrollo de esta. El concepto de universidad proveniente del latín medieval "universitas" que era designado a una colectividad que se reunía con fines no necesariamente académicos. Solo Hacia finales del siglo 14 este término se termina usando para denominar a colectividades académicas, pero cuando se usaba en su sentido moderno denotando un cuerpo dedicado a la enseñanza y a la educación requería la adicción de un complemento para redondear su significado.

No se puede decir abiertamente cual fue la primera universidad establecida, porque en la historia de la humanidad podemos encontrar la existencia de comunidades académicas que existían mucho antes que el termino universitas fuera empleado, por ejemplo el profesor Felix Patiño Restrepo en su documento "Evolucion Historica de la Universidad" propone que la primera universidad fue el museo de Alejandría.

Sin embargo, diferentes fuentes de información, datan como referente la primera universidad la universidad de Bolonia, fundada al principio del siglo XII (año 1119), en la cual los estudios sobre leyes tenían mucho prestigio pero colateralmente impartían estudios sobre teología, matemáticas, filosofía, astronomía, medicina y farmacia. En tanto en Constantinopla Constancio II creó la que se cree la primera universidad del mundo al fundar, en el 340, la Universidad de Constantinopla, aunque luego fuera reformada por el emperador Teodosio II en 425. En ella se enseñaba Gramática, Retórica,Derecho, Filosofía, Matemática, Astronomía y Medicina.
La universidad constaba de grandes salones de conferencias, donde enseñaban sus 31 profesores. Por eso podemos decir que el origen de las universidades en el mundo es un campo muy abierto para hablar, pero en si el propósito de su creación fue la educación académica que ha variado $y$ evolucionado con respecto al tiempo y el contexto.

El concepto de universidad proveniente del latín medieval "universitas" que era designado a una colectividad que se reunía con fines no necesariamente académicos. Solo Hacia finales del siglo 14 este término se termina usando para denominar a colectividades académicas, pero cuando se usaba en su sentido moderno denotando un cuerpo dedicado a la enseñanza y a la educación requería la adicción de un complemento para redondear su significado.

El término universidad fue creado por Cicerón, la palabra universum proviene del latín universus compuesta de unus (1) versus girado o convertido. Es decir uno y todo lo que lo rodea. La palabra unus expresa un integral que no admite división. La Real Académica Española lo define del latín universitas, ātis 'universalidad, totalidad', 'colectividad', 'gremio, corporación', en lat. mediev. 'institución de enseñanza superior'.

Consideremos en primer lugar (Relancio, 200, p. 327) menciona que el nombre de "universidad" no se empezó a utilizar de forma usual hasta finales de la Edad Media, en los primeros términos el mismo autor menciona que se le nombraba "Studium generale" conformada por una autoridad de carácter universal (El papa, emperador, monarcas o autoridades municipales). Así mismo en términos jurídicos la define como: un gremio una hermandad (Relancio, 200, p. 328) el cual está referido a comunidades de maestros y alumnos dedicados a la educación.

Es importante mencionar que retoman los aspectos jurídicos pues sirvieron base para crear identidad y obediencia lo cual estableció un control interno, independientemente de las autoridades externas tanto religiosas como laicas, con la finalidad de mantener un control interno el cual sirviera para mantener una gerarquia. 
A partir de los siglos XI y XII, nace la universidad contemporánea nace como "Universitas Scholarium" la cual estaba considerada como un gremio de estudiantes para después convertirse en "Universitas Magistroum" estos últimos considerados como un gremio de maestros, es importante considerar que el término "Universitas" de origen latino, (Moncada, 2008, p.132) lo define como conjunto integral y completo de los seres particulares constituidos en una colectividad determinada.

Con base en lo anterior Velázquez y Morales, en su publicación Historia y Preeminencia de la Universidad Occidental consideran a los "Universitas Magistrorum et Scholarium" como un ayuntamiento de maestros y de escolares, el cual denota un cuerpo dedicado a la enseñanza y a la educación y otros fines no necesariamente académicos.

La mayoría de las universidades del sur de Francia, Italia y España basaban sus enseñanzas en el estudio de Derecho era lo primordial y la medicina ocupaba un segundo lugar (Relancio, 2007, p.337) a diferencia de las artes estas estaban orientadas más a la práctica pues la retórica era un auxiliar fundamental en leyes, y la filosofía natural un instrumento para la medicina. (Relancio, 2007, p.337)

Finalmente Relancio en su texto Las universidades medievales (2007) recupera la parte central de la enseñanza la cual estaba basada principalmente en las artes preparatorias, o artes liberales; por una parte el Trivium: el cual se encargaba de la enseñanza de la gramática, retórica y lógica; y el quadrivium: enfocado a la aritmética, geometría, música y astronomía.

Con base en lo anterior se hará una revisión histórica acerca de los modelos que han realizado aportes significativos en la enseñanza a lo largo de la historia, destacando métodos de enseñanza, organización administrativa y académica entre otros.

\section{Modelo Medieval}

El origen de las Universidades medievales se remota a los siglos XIV y XV se caracterizan por comunidades entre maestros y universitas cuya principal función es la enseñanza, consideremos que antes de este siglo no se acuñaba el término "Universidad".
Se le llamaba Studium generale la cual estaba considerada como la Institución de Educación superior, regida por una autoridad de carácter universal, la enseñanza se basaba principalmente en el Derecho, Medicina y Teología. Relancio, en su texto Las Universidades Medievales hace referencia a la forma de enseñanza específicamente el trívium que consistía en la enseñanza de la Gramática, Retórica y Lógica; y el quadrivium que se encargaba del estudio de la Aritmética, Geometría, Música y Astronomía. Las universidades en la edad media estaban distribuidas por facultades, Relancio menciona con respecto al sistema de enseñanza la siguiente cita textual, retomada de su texto Las Universidades Medievales:

En cuanto a los métodos de enseñanza, a pesar de los cambios de detalle que diferenciaban a unas universidades, o facultades, de otras, y de los cambios acaecidos a lo largo del tiempo, sí se podría hablar de una metodología similar en todos los casos, que podría llamarse escolástica. Estos métodos provenían de las escuelas del siglo Xl: las escuelas de lógica y teología de París por ejemplo, las escuelas de derecho de Bolonia o las de medicina de Salemo. (Relancio, 2007 p. 330,331 )

Este mismo autor destaca aportes de las siguientes universidades, el cual se realizó de manera personal retomando sus aportes de su artículo Las Universidades Medievales:

\begin{tabular}{|c|c|c|}
\hline Universidad & Característica & Enseñanza \\
\hline $\begin{array}{l}\text { Universidades } \\
\text { de Bolonia y } \\
\text { Padua. }\end{array}$ & $\begin{array}{l}\text { Tienen su propia } \\
\text { organización "el colegio } \\
\text { de doctores" Agrupados } \\
\text { por especialidad. } \\
\text { Universidades } \\
\text { Autónomas. }\end{array}$ & $\begin{array}{l}\text { Artes, medicina o } \\
\text { derecho. }\end{array}$ \\
\hline $\begin{array}{l}\text { Universidad de } \\
\text { Montpellier }\end{array}$ & $\begin{array}{l}\text { estaba bajo la autoridad } \\
\text { de la Iglesia }\end{array}$ & $\begin{array}{l}\text { En Montpellier. } \\
\text { Medicina y derecho } \\
\text { (permanecieron } \\
\text { separadas) }\end{array}$ \\
\hline $\begin{array}{l}\text { Universidad de } \\
\text { Oxford }\end{array}$ & $\begin{array}{l}\text { Establecimientos } \\
\text { eclesiásticos. } \\
\text { Tuvo influencia de la } \\
\text { universidad de París. }\end{array}$ & filosofía natural \\
\hline $\begin{array}{l}\text { Universidad de } \\
\text { Salamanca }\end{array}$ & $\begin{array}{l}\text { Regida bajo control } \\
\text { eclesiástico, Seguía un } \\
\text { modelo mixto con } \\
\text { elementos de Bolonia y } \\
\text { de París. }\end{array}$ & $\begin{array}{l}\text { Artes liberales y } \\
\text { teología }\end{array}$ \\
\hline $\begin{array}{l}\text { Universidad de } \\
\text { Paris }\end{array}$ & $\begin{array}{l}\text { Se constituyó como } \\
\text { asociación de todos los } \\
\text { colegios preexistentes en } \\
\text { la ciudad de París }\end{array}$ & $\begin{array}{l}\text { Filosofía práctica y } \\
\text { Teología }\end{array}$ \\
\hline
\end{tabular}

Fuente: Planteamientos expuestos por Relancio, Alberto. (2007). Las Universidades Medievales, Ciencia y cultura en la edad media, actas VIII y X, Canarias. ISBN: 848309-048

SALGADO-VARGAS, Christian Karel, ESCOBAR-ELIGIA, Francisco y ROMERO-ROMERO, Araceli. La Sociedad del Conocimiento para el Desarrollo Humano desde la perspectiva de distintos modelos educativos. Revista de Ciencias de la Educación. 2019 
En el cuadro anterior se pueden observar las características principales por cada universidad, así como las materias que enseñaban en su mayoría enfocadas al estudio de la filosofía, medicina y el derecho.

Un aspecto importante en estas Universidades es el idioma principal en la enseñanza en la edad media siendo este el latín. Existían además dos tipos de ejercicios básicos en todas las facultades, la "lección" y la disputa" las cuales tenían una serie de consecuencias como a continuación se retoma textual (Relancio, 2007 p. 331):

1. Se daba un papel crucial y propedéutico a la gramática y a la dialéctica, si uno quería comprender cabalmente los textos y desarrollar razonamientos lógicos coherentes para acceder a la verdad.

2. Se dio una importancia básica a la escritura, en cuanto los libros eran la fuente de autoridad, tanto de los autores de referencia como de sus comentaristas o glosadores; pero, al mismo tiempo que esto era importante, luego aprendido se manifestaba en el lenguaje oral en las lecciones leídas en voz alta y, más aún, en las disputas.

3. La relación maestro-discípulo era muy estrecha y necesaria.

4. Se recurría como recurso indispensable a la memorización y repetición de textos, que exigía estudios de muy larga duración, que podía ir de los cuatro o cinco años para una facultad de artes, pasando por los doce o trece de ciertas facultades de derecho, hasta los quince o dieciséis años de la facultad de teología de París.

5. Esta forma de pedagogía ahogó cualquier intento por introducir otros métodos de estudio y enseñanza (experimentación, análisis filológico e histórico, etc.).

En este periodo la evaluación se demostraba a través de la aplicación de exámenes orales los cuales Renancio define como aquellos que son considerados como la culminación normal de un programa de estudios, que daba derecho a obtener un título oficial. (Relancio, 2007 p. 331).

\section{Modelo Francés}

En las siguientes líneas se realizará una reflexión en torno al modelo francés como antecedente de la educación universitaria. La Real Académica Española define el concepto modelo como un arquetipo o punto de referencia para imitarlo o reproducirlo, de ahí que la ciencia hoy en día y todas sus disciplinas del conocimiento trabajen hoy a partir de modelos, que pretenden esquematizar realidades complejas que faciliten su comprensión.

Antecede al surgimiento de este modelo, concebido en Francia, país que contaba con una alta densidad de población, la existencia de sociedades científicas, como respuesta a las exigencias de aquellos tiempos y que versaban en las diversas maneras de abordar la ciencia.

El siglo XVIII se caracterizó por su crecimiento y desarrollo económico en Europa; el ámbito educativo no podía ser la excepción donde el llamado Estado Napoleónico fungió como forjador de una nueva organización universitaria, capaz de satisfacer los múltiples requerimientos que la sociedad imperial planteaba para la educación (Mureddu, 2018).

Prelot (como se citó en Arredondo,2011) indica que con la llegada a Napoleón al poder se crea esta institución para controlar y regular todos los aspectos de la enseñanza en cualquier nivel, denominándola la Universidad Imperial definida como aquella dedicada exclusivamente a la enseñanza y educación pública de todo el imperio.

Resulta interesante destacar la habilidad del mandatario para que a través del famoso Plan de Rapport, pronunciado en la Asamblea Legislativa Francesa, se establezca el procedimiento mediante el cual Estado toma la titularidad de la labor educativa y tome el control de la sociedad y que desde ese entonces se le reconozca la trascendencia e importancia de la educación desarrollo y modernización de las comunidades.

Napoleón no concebía otro tipo de institución que no fuera pública, dado que le permitía mantenerla sometida al poder del Estado, quién tomó la decisión de suprimir la filosofía y la literatura de los contenidos, por considerarse disciplinas que invitaban a los alumnos a pensar y a ser críticos (Arredondo, 2011).

SALGADO-VARGAS, Christian Karel, ESCOBAR-ELIGIA, Francisco y ROMERO-ROMERO, Araceli. La Sociedad del Conocimiento para el Desarrollo Humano desde la perspectiva de distintos modelos educativos. Revista de Ciencias de la Educación. 2019 
De acuerdo con Mureddu (2018), la Universidad en Francia incorpora el término "profesiones" y divide las actividades académicas. Las facultades eran instancias de administración curricular, integradas por Escuelas Profesionales que elaboraban los "currícula" de cada profesión. Fue durante el periodo de mandato de Napoleón cuando la Universidad comienza a otorgar licencias para ejercer el titulo ostentado.

El autor añade que las Escuelas fueron atendidas por profesores, que se encontraban habilitados para enseñar, pero eran necesariamente maestros dedicados a la investigación y al cultivo del saber. Los investigadores se agrupaban a través de institutos que se enfocaban totalmente al estudio, ellos esporádicamente dictaban cátedras.

Este modelo contempla a las Escuelas de Altos Estudios, las cuales para su ingreso requerían el haber cursado una carrera en las Facultades Universitarias. Se crea también la Escuela Normal dirigida a formar maestros de enseñanza media y media superior. El nivel medio superior, preparatorio para el ingreso a la universidad fue confiado al Liceo, institución que perdura hoy en día en Francia.

Este modelo de universidad, dista del espíritu que impera en la actualidad y que es el de generar un espacio de discusión de ideas e intercambio de conocimiento en beneficio de la sociedad. Como medio represor, el modelo francés sirvió en su momento para la consolidación de un imperio que buscaba la dominación y supremacía mundial. Cada vez más se hace presente el sentido de cooperación y ayuda mutua en aras de generar universidades de calidad.

La creación y puesta en marcha de un modelo lleva a la idea de que con él, se instaure un orden y la organización actúe con un adecuado conjunto de normas establecidas, que garantice gobernabilidad.

\section{Modelo Inglés}

Actualmente existen diversas maneras de catalogar las universidades y más aún aquellas que marcaron trascendencia por: su historia en el mundo contemporáneo, por los modelos que marcaron pauta en la evolución de los métodos de enseñanza actual.
Sin duda uno de los modelos con mayor relevancia es el Modelo Inglés o Modelo Anglosajón, representado principalmente por la Universidad de Oxford y la de Cambridge, su principal aporte es brindar una educación de carácter general y liberal, surge en los siglos XII y XIII por medio de los colleges (UAEM, 2005 p. 47). Colegios autónomos que destacan, sobre todo, en la formación humanística y teológica, de tipo obligatorio el cual se encuentra subdividido por Departamentos o Estados, los cuales se encargan de asumir las políticas educativas, en la actualidad los colegios universitarios también conocidos como "colegios comunitarios" en Estados Unidos de Norte América.

Con base en lo anterior los una de las funciones sustanciales y que dieron origen a este modelo se debe a las problemáticas de una sociedad industrializada y enfocada en la producción y el consumo, como lo fue la sociedad estadounidense a finales del siglo XIX $\mathrm{y}$ principios del $\mathrm{XX}$, que requería de una instrucción eficiente para enfrentarse a la creciente urbanización e industrialización y a su vez, la administración eficiente y eficaz de tal sistema (Cossio, 2017, p. 8)

Es de esta manera que los estadounidenses sugieren el equilibrio entre el trabajo y el estudio, de manera que no exista un exceso de trabajo lo cual se equilibra, es a partir de esto que se han elaborado teorías educativas basadas en la psicología haciendo énfasis en el aprendizaje como el conductismo, el constructivismo, el cognitivismo (Cossio, 2017, p. 8),

Entre las universidades que rescatan este modelo la Revista electrónica de pedagogía, destaca en su escrito "Los modelos clásicos de universidad pública" destaca las siguientes universidades:

Universidad de Pensylvania. Hacia 1779 este College se convierte en la Universidad de Pensylvania, la primera universidad pública en este país.

Universidad de Virginia. A principios del siglo XIX, continuó la oposición a los colleges tradicionalistas y elitistas, se establecía una estructura académica que difería de los colleges coloniales. Integrados a ocho colleges o departamentos diferentes. 
Universidad de Harvard. Casi al mismo tiempo (1825), Harvard estableció instancias académicas denominadas departamentos para supervisar varios cursos paralelos. Establecio el sistema electivo, la incorporación de las artes liberales al pregrado en el college, la instauración del posgrado, así como de las escuelas profesionales y la promoción de la integración de la docencia y la investigación.

Otra de las características principales de los Colleges es el sistema tutorial el cual se basaba en la doctrina in loco parentis, es decir, la Universidad asumía el lugar de los padres (UAEM, 2005 p. 47) a los profesores se les designaba un número de estudiantes, con los cuales de dedicaría a su formación, moral y valores que promovía la iglesia anglicana. A partir de la creación de estas Universidades, se denota una fuerte demanda universitaria representada por estas dos universidades lideradas por grupos de profesionales liberales, apegados a los estudios clásicos, clave en la enseñanza liberal; en la cual el sistema educativo está basado en una formación profesional liberal. Es decir, centrado en la formación del hombre y en la investigación.

Por otra parte, las Universidades Anglosajonas a partir del siglo XIX promueven el desarrollo económico, la propiedad social de la universidad se garantizaba a través del nombramiento de un Consejo de Trustees constituido por ciudadanos no académicos (Apaza, 2007 p. 4) Es entonces, que el modelo norteamericano es caracterizado por demandas sociales y por una organización empresarial de las estructuras internas. Por consiguiente, el poder que ejerce el gobierno sobre las universidades es débil basándose principalmente en financiación y a establecer criterios muy generales sobre las políticas del sistema de educación superior (Apaza, 2007 p. 4).

La Autonomía universitaria en este modelo se reduce al respeto a la libertad académica donde aquellos académicos con mayor prestigio poseen el más alto reconocimiento institucional, ya que en la cultura pedagógica anglosajona ha servido para la elaboración de teorías educativas, es por tal motivo que el modelo anglosajón va a circunscribir su ámbito de aplicación a los países de habla inglesa y el francés se va a extender a toda Europa occidental.

\section{Modelo Universitario Norteamericano}

La presente revisión se desarrolla en tres premisas; en primer lugar, por la conquista que llevaron a cabo las doce colonias inglesas en territorio norteamericano, el desarrollo universitario de ese país, tomará como referencia el modelo inglés. Su afán por una enseñanza liberal y general a través de una metodología tutorial. Méndez (2017) afirma: "poco a poco, debido a un progresivo aumento de la población estudiantil en las primeras universidades este modelo fue perdiendo vigencia, y fue sustituido por el modelo alemán a través de científicos ilustres exiliados por el movimiento nazi" (p.101).

En segundo lugar, hoy día la educación universitaria en Estados Unidos es muy compleja puesto que el país es una unión de estados, cada uno de los cuales tiene completo control de sus sistemas educativos. Así lo considera Gómez (2013) cuando sostiene que: "en muchos estados, el control de la educación ha sido delegado a las comunidades locales; así hay una gran variedad de programas y procedimientos" (p.123). Sin embargo, estas cuestiones son comunes en todos los sistemas estatales en los Estados Unidos de América.

En tercer lugar, los orígenes de la educación estadounidense pueden encontrarse en instituciones religiosas privadas. El Colegio de Harvard es un ejemplo. Asímismo Gómez reafirma que en su origen (1642) esta universidad estuvo destinada a la educación de los pastores de las iglesias congregantes, así como a cierto número de indios seleccionados. De igual manera nos dice: "los colegios de Nueva Inglaterra, fueron construidos de acuerdo al modelo inglés, y mantuvieron ciertas connotaciones religiosas y latinas, por ejemplo, los colegios de Pensilvania, Maryland y el de Wlliam Mary, abierto en Virginia, reflejan las aspiraciones religiosas de estas regiones" (Gómez, 2013, p. 127).

Pero a pesar que este modelo educativo es parte del desarrollo histórico inicial norteamericano, ello no impide que dejen de estar alienados a las instituciones religiosas, ya que el autor así lo expresa: "un gran número de los más de dos mil establecimientos de educación superior siguen bajo el control de los organismos religiosos, aunque por lo general son poco importantes y tienden cada vez más a la secularización". (Gómez, 2013, p. 127)

SALGADO-VARGAS, Christian Karel, ESCOBAR-ELIGIA, Francisco y ROMERO-ROMERO, Araceli. La Sociedad del Conocimiento para el Desarrollo Humano desde la perspectiva de distintos modelos educativos. Revista de Ciencias de la Educación. 2019 
Aunque las instituciones norteamericanas se modificaron con el tiempo y con el crecimiento de la cultura urbana y de los intereses comerciales, por recomendación de Jefferson para la educación de los jóvenes de esa época sé tomó el modelo europeo de corte latino que surgió con el Siglo de las Luces o la IFigura , aunque estudiando más a fondo se encuentra que los orígenes del sistema universitario estadounidense son generalmente remitidos a un ciclo de reformas que se inició a fines del siglo XIX y que culminaron en los años veinte del siglo pasado, que fue, nos dice Gómez (2013): "Cuando la mayoría de los Colleges y universidades adoptaron estructuras institucionales, rutinas docentes y sistemas financieros que se asemejan a las corporaciones modernas" (p. 136).

$\mathrm{Y}$ es precisamente en el siglo XIX cuando la principal fuente de benefactores privados empezó a cambiar al pasar de las congregaciones religiosas e individuales a una naciente red de fundaciones privadas de apoyo, entre las más importantes de estas fundaciones educativas fueron: "el Consejo General de educación (GEB), fundado en 1903 por John Rockefeller y la Fundación Carnegie para el Avance de la enseñanza (CFAT), fundada en 1906 por Andrew Carnegie" (Gómez, 2013, p.142).

Actualmente en los Estados Unidos -esto sucede en todo el mundo académico- se observan cada vez más las distinciones entre el sector público y privado1, sin embargo todavía hay importantes características distintivas entre ambos sectores en lo que se refiere a la situación legal sobre cuestiones de autonomía y responsabilidad.

Aunque la expansión de los programas federales destinados a la educación superior se disparararon durante la segunda Guerra Mundial, simultaneamente hubo un aumento masivo de los programas federales para la investigación y el desarrollo. Merced a lo que nos refiere Gómez (2013) “...el Departamento de Defensa, la Comisión de energía Atómica, el Instituto Nacional de Salud y la Fundación Nacional de la Ciencia, fueron fuentes de la financiación federal para la investigación y el desarrollo" (p. 156).

\footnotetext{
${ }^{1}$ Este último se vuelve cada vez con mayor frecuencia hacia el estado, para solicitarle ayuda financiera, en tanto que el primero consigue un creciente apoyo gubernamental

Algunos otros ensayistas como Covían (2015) consideran que fueron tres las raíces de la universidad norteamericana:

1. Los colegios del Este del país, inspirados en la tradición universitaria inglesa.

2. Las Escuelas de Agricultura y Artes Mecánicas, cuya fundación tiene lugar durante la guerra civil.

3. La reforma basada en el informe Flexner, que introduce el modelo alemán en la enseñanza superior norteamericana a principios del siglo XX.(p. 11)

La esencia de esta reforma que se dio en el siglo pasado consiste hasta ahora en la investigación científica como ingrediente fundamental de la actividad universitaria y también en la exaltación de la figura del profesor, la agrupación de la enseñanza, la investigación en los institutos universitarios, la libertad de enseñanza y aprendizaje.

Resumiendo, los comentarios que puedan hacerse en relación con las tres raíces mencionadas sobre la universidad estadounidense y de las reformas implantadas desde el siglo XX, no bastan, para dar una idea completa de sus características. Existen otros hechos relevantes que de alguna manera se mencionaron al inició de este artículo, y que pueden ayudar a comprender el estado actual del modelo estadounidense.

Por ejemplo, que no existe un sistema universitario dependiente del gobierno federal, que las universidades tradicionales son instituciones privadas y representan la continuación de los primitivos colegios basados originalmente en la tradición inglesa y finalmente que las universidades estatales son mantenidas por los gobiernos de los correspondientes Estados y representan en muchos casos la continuación de los primitivos colegios de Agricultura e Ingeniería creados por la Ley Morrill. Ambas clases de universidades son organismos autónomos que se rigen por sus propios estatutos. 


\section{Modelo Alemán}

El modelo alemán se concibe en el siglo XIX con una intensa carga política a cuestas. A decir de Arredondo (2011) este modelo y el francés, son los precursores de la Universidad contemporánea. Se considera a Humboldt como el padre de la Universidad Alemana, que retoma a Herder, Fichte y Schleiermacher, herederos a su vez de Kant y Hegel quienes conciben en el estudio de la ciencia pura, lo que derivó un replanteamiento de modelo preparatorio para el ingreso a la Universidad (Mureddu, 2018).

De acuerdo con (Mureddu, 2018) la Universidad Germana supone “...que la ciencia se cultiva en las Academias, es -decir, entre los maestros ya consagrados a ella. Los estudiantes, por el contrario, apenas han iniciado en los primeros ejercicios intelectuales, en el Gimnasium. Por tanto, la universidad se concibe como el punto de reunión de ambos contingentes"(p.9). En este contexto la Universidad contemporanea de acuerdo con el modelo Alemán supone reunir ambos sectores, tanto maestros como estudiantes y con ello reordenar la vieja estructura, en donde el estado tenía el control de la educación.

Este modelo propone congregar a los profesores, expertos en determinada área del conocimiento, en academias. En este esquema, la titularidad de un departamento llevaba implícita la adhesión al sector docente. También concibe el hábito autodidacta que a su vez contribuyó en el desarrollo de profesionistas al tiempo que formaba científicos y expertos. Motivo por el cual se organizó en en los departamentos disciplinarios que se integraron en cada facultad alemana.

Espejo y Martínez (2001) afirman que a nivel educativo existen tres criterios que permiten clasificar los sistemas nacionales: Micromodelos, Mesomodelos y Macromodelos. Éste último podría agruparse de la siguiente manera:

\begin{tabular}{|c|c|c|c|c|}
\hline $\begin{array}{l}\text { Centraliz } \\
\text { ado }\end{array}$ & $\begin{array}{l}\text { Descentraliz } \\
\text { ación } \\
\text { intermedia o } \\
\text { modelo } \\
\text { autonómico }\end{array}$ & $\begin{array}{l}\text { Descentraliz } \\
\text { ación federal }\end{array}$ & $\begin{array}{c}\text { Descentraliz } \\
\text { ación federal } \\
\text { y comunal }\end{array}$ & $\begin{array}{c}\text { Descentraliz } \\
\text { ación } \\
\text { comunal y } \\
\text { académica }\end{array}$ \\
\hline $\begin{array}{l}\text { Francia, } \\
\text { Portugal, } \\
\text { Grecia, } \\
\text { Irlanda, } \\
\text { Luxembu } \\
\text { rgo } \\
\text { algunos } \\
\text { países } \\
\text { africanos, } \\
\text { árabes, } \\
\text { asiáticos } \\
\text { y } \\
\text { oceánicos }\end{array}$ & $\begin{array}{ll}\text { España } & \mathrm{e} \\
\text { Italia } & \end{array}$ & $\begin{array}{l}\text { Alemania, } \\
\text { Australia y } \\
\text { Brasil }\end{array}$ & $\begin{array}{ll}\text { Suiza } & \text { y } \\
\text { Estados } & \\
\text { Unidos } & \end{array}$ & Reino Unido \\
\hline
\end{tabular}

Tabla 1 Clasificación de Sistemas Educativos Nacionales Fuente: Espejo y Martínez (2001

Como resultado de la ampliación al modelo, la Universidad se vio inmersa en una paradoja: en un extremo, la población estudiantil aumentó y en el otro, se restringió, pues la reflexión sobre las aspiraciones más profundas y genuinas del hombre y de la sociedad se desarrollaron en el ámbito político, entre otros, más que en el educativo (Mureddu, 2018).

Contrastando el modelo alemán y el francés se puede observar la diferencia en el desarrollo de la educación como disciplina académica en donde se tenía como finalidad, el formar profesionistas; asímismo, realizar investigación y contribuir al desarrollo de la ciencia. Schriewer, J., \& Keiner, E. (1997) afirman que: “...para 1987 más de mil profesores universitarios enseñaban o hacían investigación educativa en la República Federal de Alemania, mientras que el número equivalente en Francia fue menor a cincuenta ${ }^{2}$ " (p.4).

Desde el punto de vista estructural, en la década de 1970 el modelo alemán ha cambiado sobre todo el ámbito de secundaria II, es decir, la fase superior del Gymnasium. Hoy en día el sistema educativo en Alemania ofrece a los alumnos del ciclo superior opciones que les permiten formarse en mayor medida en función de sus propias capacidades e intereses. Los estudiantes en Alemania elijen las asignaturas en dos vertientes: intensivas o troncales.

\footnotetext{
${ }^{2}$ Para Alemania, véase Jürgen Baumert y Peter M. Roeder. Zur personellen Situation in der Erziehungswissenschaft an den Wissenschaftlichen hochschulen der Bundesrepublik Deutschland, Berlín: Max-Planck-Institut für Bildungsforschung, 1989. Para Francia, véase G. Vigarello (dir.) Les Sciences de l'éducation: Enjeux et finalités, París: ISSN: 2523-2436

ECORFAN® Todos los derechos reservados
}

Association des Enseignants et Chercheurs en Science de l'éducation, 1985. 
El currículo puede modificarse por el profesor de acuerdo con el contexto escolar, lo que puede resultar contraproducente a la hora de ingresar a la Universidad porque el alumno no recibe un contenido homólogo de asignaturas cursadas.

\section{Modelo Universitario en México}

Hablar de la Educación Superior en México es retomar antecedentes de la Universidad Nacional Autónoma de México, la Universidad con más antigüedad en el continente americano y una de las más prestigiadas en América Latina, evolucionando con el paso de los años, adaptándose a los movimientos sociales y creando una historia en cada etapa. De ahí la importancia de destacar aspectos relevantes del origen de la Universidad en México.

En sus inicios, la UNAM se funda en el siglo XVI, en la época colonial se distinguió como institución clave del poder peninsular en la Nueva España, la universidad colonial de México fue fundada por real cédula del 21 de septiembre de 1551, (Marsiske, 2006, p. 9) desapareciendo a principios del siglo XIX, para el siglo XX se destaca por su nueva estructura académica, la educación en México resalta dos objetivos: impartir educación superior para formar técnicos, profesionales, investigadores, profesores universitarios ..., realizar investigación y difundir la cultura (Ibarrola, 1986, p. 3).

Cabe destacar que la educación en México para el año 1537 crea el Colegio de Santa Cruz de Tialteloico, destinado especialmente a la población indígena del país (Ibarrola, 1986, p. 4). Resalta la educación elemental y educación superior, en esta última se acentúan los estudios filosóficos y literarios, por su parte la Universidad de México ofrecía estudios en teología y de derecho canónico, cabe destacar que el Papa, como jefe de la Iglesia, sancionara también dichos estudios (Marsiske, 2006, p. 9), es hasta finales del siglo XVIII que la Real Universidad de México, decide llamarse a sí misma Real y Pontificia.

En esta última institución la Universidad Real y Pontificia de México fundada en 1551 para el siglo XVI, ofrece estudios de Teología, Escrituras Sagradas, Cánones, Decretos, Instituto y Leyes (Ibarrola, 1986, p. 4).
Esta universidad es creada por la corona Española, a finales del siglo XVIII se crea el Colegio de Minería y el Jardín Botánico y como resultado del logro de independencia se crean los colegios de San Ildefonso, San Gregorio, San Juan de Letrán y Minería, la Escuela de Medicina, la Academia de San Carlos y el Colegio Militar. (Ibarrola, 1986, p. 5).

La organización de la Real Universidad de México se distingue por tres niveles, el corporativo, por el cual la Universidad se autogobernaba a través de los distintos claustros; en segundo lugar, el administrativo y financiero; por último, el académico (Marsiske, 2006, p. 14) este último incluía la provisión y lectura de cátedras, los grados que se concedían a quienes cursaban las lecciones y tomaban parte en dichos actos.

Para el año 1910 la educación superior en México se transforma con la inauguración de la Universidad Nacional de México, que reúne a escuelas nacionales fundadas a lo largo del siglo XIX incorporando la Preparatoria, Estudios de Jurisprudencia, Medicina, Ingeniería, de Bellas Artes- y a la recién creada Escuela de Altos Estudios, Modificando en 1929 la Ley Orgánica dando una autonomía limitada a la Universidad, una autonomía completa en la Ley Orgánica de 1933, desligándose el Estado mexicano. (Marsiske, 2006, p. 11) y se destaca en 1921 la creación de la Secretaría de Educación Pública al mando de José Vasconcelos para dirigirla.

Cabe destacar que a partir de 1920, los Institutos Científicos y Literarios se empiezan a transformar en lo que ahora son las universidades estatales, entre estos el Instituto Científico y Literario de Toluca.

Dentro de la enseñanza de la educación superior en México se destaca la creación del Instituto Politécnico Nacional (IPN, creación en 1936), en el cual se une la clase obrera prevocacional, técnicos y profesionales de escuelas superiores y nacionales, promoviendo carreras de Ingeniería, Administración y Economía, principalmente. 
En el año 1953 se da inicio a la nueva Universidad, y para 1966 la oferta de educación superior en México se había diversificado ofreciendo estudios en 83 instituciones, de los cuales 33 eran universidades, 20 institutos, 25 escuelas superiores y 5 centros. (Marsiske, 2006, p. 24) para 1974, se crea la Universidad Autónoma Metropolitana (UAM), 28 institutos tecnológicos regionales, 17 institutos tecnológicos agropecuarios en zonas rurales, y 3 de ciencia y tecnología del mar para las ciudades costeras.

Es hasta la administración del presidente Carlos Salinas de Gortari que surge el Plan Nacional para la Modernización Educativa y se expide la Ley General de Educación el cual sustituye a la Ley Federal de Educación, es entonces que actualmente las Instituciones de Educación Superior (IES) del país se dedicándose a la investigación, generación de conocimiento, renovación científica y tecnológicos que demanda la sociedad.

\section{La UAEM y la educación basada en competencias}

Antes de la revisar la incorporación de la educación basada en competencias en el nivel licenciatura de la UAEM, es necesario comprender que la Universidad cuenta con un modelo educativo sustentado en su Ley, el Estatuto Universitario, el Reglamento de Estudios Profesionales, y el Reglamento de Facultades y Escuelas Profesionales.

Es importante diferenciar este modelo educativo de lo que se ha llamado Modelo Institucional de Innovación Curricular (MIIC) y que, visto en perspectiva, fue el instrumento o proyecto institucional para conducir la reforma académica de 2003 y 2004, sin que éste substituya al primero.

El Modelo Institucional de Innovación Curricular (MIIC), no puede confundirse con este modelo educativo de la Universidad, pues tan solo constituyó un proyecto para hacer más asequibles los objetivos de la docencia universitaria y particularmente, los objetivos de los estudios de licenciatura.
El proyecto del MIIC, inició en el 2001. Entre los problemas que justificaron la innovación en los currícula de los estudios profesionales, Medina y Espinoza (2002) citan: el predominio de carreras con perfiles y modalidades inalteradas desde su creación, la duración uniforme de los estudios, inexistencia de salidas alternativas, el aislamiento y autosuficiencia de escuelas y carreras, la formación cultural unilateral y fragmentaria, el formalismo reglamentario y administrativo, el estancamiento en métodos pedagógicos, el academicismo que desvincula la escuela con el entorno social y productivo, y las concepciones y prácticas de evaluación con bajo impacto educativo.

Dicho proceso de innovación se impulsó desde cuatro ejes metodológicos: la planeación educativa, el diseño curricular, la formación y actualización de profesores, y la programación pedagógica. Desde esta perspectiva, se buscó instaurar un nuevo modelo de formación profesional, concretándose en la reforma a los 61 planes de estudio que se impartían, en ese entonces, mediante 124 programas educativos, en 21 Organismos Académicos y 9 Unidades Académicas Profesionales.

Entre los rasgos que asumió este modelo para la formación profesional destacan: el rediseño de planes de estudio por competencias profesionales, la organización de los contenidos por núcleos de formación, la incorporación de la transversalidad para la formación universitaria, el rediseño de los planes de estudio y su administración para la flexibilidad curricular (créditos, áreas de acentuación, elección de carga académica), la instrumentación del servicio de tutoría académica para apoyar el tránsito y desempeño del alumno, la incorporación del idioma extranjero como asignatura curricular, el impulso a la didáctica centrada en el alumno, la incorporación de modalidades educativas semi y no presenciales, y la evaluación por competencias para acreditar la formación por auto aprendizaje.

\section{Las Sociedades del Conocimiento}

En la idea de concebir un modelo de universidad en el que se tenga una participación cada vez más activa en la sociedad y ésta contribuya en la solución de problemática local en un contexto global, surgen las llamadas sociedades del conocimiento como consecuencia a los cambios y el surgimiento del concepto de globalización.

SALGADO-VARGAS, Christian Karel, ESCOBAR-ELIGIA, Francisco y ROMERO-ROMERO, Araceli. La Sociedad del Conocimiento para el Desarrollo Humano desde la perspectiva de distintos modelos educativos. Revista de Ciencias de la Educación. 2019 
En este escenario el entorno educativo objeto de estudio, se caracteriza por un rompimiento de fronteras que se traduce en oportunidades para la generación de una institución colaborativa. No se pone en duda el papel de la generación de conocimiento como parte del crecimiento económico, político, tecnológico, social y pilar fundamental en el desarrollo humano en el mundo. Lo que es imperante analizar, es la manera en la que las sociedades del conocimiento se relacionan e interaccionan en la construcción del conocimiento global.

El término sociedad del conocimiento ocupa un lugar estelar en la discusión actual en las ciencias sociales así como en la política europea. Se trata de un concepto que aparentemente resume las transformaciones sociales que se están produciendo en la sociedad moderna y sirve para el análisis de estas transformaciones. Al mismo tiempo, ofrece una visión del futuro para guiar normativamente las acciones políticas. (Krüger, 2006, p.1)

Este concepto se utiliza para describir los cambios sociales en las sociedades actuales (Krüger, 2006). En las líneas subsecuentes se realiza un análisis de las características de este ordenamiento social con la idea de comprender y destacar la importancia del conocimiento como detonador del desarrollo económico mundial.

En el informe mundial de la Organización de las Naciones Unidas para la Educación, la Ciencia y la Cultura establece que un elemento central de las sociedades del conocimiento es la "Capacidad para identificar, producir, tratar, transformar, difundir y utilizar la información con vistas a crear y aplicar los conocimientos necesarios para el desarrollo humano" (UNESCO, 2005, p. 29). Cabe destacar que estas sociedades mantienen una visión autónoma, pluralidad, integración, solidaridad y participación. En este mismo informe se destaca que la noción de sociedades del conocimiento es más enriquecedora y promueve más la autonomía que los conceptos de tecnología y capacidad de conexión que a menudo constituyen un elemento central en los debates sobre la sociedad de la información. Se debe considerar que sólo se propiciará el desarrollo de sociedades del conocimiento y se asigna como finalidad "ir hacia un desarrollo del ser humano basado en los derechos de éste" (UNESCO, 2005, p. 29).
Con base en lo anterior se puede resaltar que tanto el Desarrollo humano y la Autonomía, son elementos centrales en las sociedades del conocimiento, lo cual permiten mejores prácticas de los derechos universales, permitiendo al mismo tempo la eficacia de la lucha contra la pobreza y de las políticas de desarrollo.

\section{Características de la sociedad mexicana del conocimiento}

Como sucede en la mayoría de las sociedades del conocimiento, permea la percepción de constituirse como un ente plural, diverso, pero también contradictorio y desigual. Estas diferencias se acentúan en la llamada brecha digital que frecuentemente se utiliza como un indicador de crecimiento. En tanto las Universidades no solventen el gran reto que implica ofrecer acceso a internet de calidad, me refiero a conexiones ininterrumpidas y constantes, limitará la participación del total de la comunidad universitaria y esto conllevará a la generación de sociedades desiguales, situación que se atenúa en función de la distribución social de la educación (Didriksson, 2007).

En relación con la era tecnológica surge un concepto, que es el de sociedad red, noción promovida por M. Castells. Se trata de una concepción situada entre la 'sociedad de la información' y la 'sociedad del conocimiento'. Al respecto Castells marca diferencias respecto a la 'sociedad de la información', distinguiendo entre información e informacional. Información, es decir comunicación del conocimiento, ha sido, según Castells, "fundamental en todas las sociedades (...).

En contraste, el término informacional indica el atributo de una forma específica de organización social en la que la generación, el procesamiento y la transmisión de la información se convierten en las fuentes fundamentales de la productividad y el poder, debido a las nuevas condiciones tecnológicas que surgen en este periodo histórico" (Castells 1996. Vol. 1. p. 47).

En México, la enseñanza superior está siendo objeto de una mercantilización y diversificación muy amplias. 
En este contexto, las instituciones tradicionales importantes como la Universidad Nacional Autónoma de México pueden desempeñar un papel de regulación y contrapeso, es por ello que en las sociedades del conocimiento, la confrontación de dos regímenes de conocimiento distintos en los proyectos de desarrollo (conocimientos científicos y conocimientos locales) plantea problemas complejos, especialmente por lo que atañe a la protección de la propiedad intelectual de los derechohabientes. (UNESCO, 2005, p. 166).

$\begin{aligned} & \text { Aportación y } \\ & \text { universidades } \\ & \text { conocimiento }\end{aligned}$
en las

Bajo el supuesto de que en una sociedad del conocimiento se hace necesaria la producción y transferencia del mismo, debe tenerse sumo cuidado con el uso y manejo de la información para prevenir un posible enfoque economista y perder de vista la carga conferida a las universidades en cuanto a producción de recursos que sirvan de punta de lanza en la generación de tecnología, en la producción científica en la apertura del debate para el caso de las humanidades y las ciencias sociales y en el desarrollo de nuevas habilidades lingüísticas que permitan el intercambio de información.

Las universidades como instituciones relacionadas a la construcción de una sociedad del conocimiento deberán entonces, revisar hasta qué punto está determinada en función del mercado laboral, por los intereses de la empresa, la sociedad, el estado de manera tal que el sentido de la misma se vea impulsado en un enfoque que privilegie el desarrollo humano a fin de aportar soluciones que generen condiciones de bienestar e igualdad.

Finalmente cabe destacar que un estudio realizado por el Instituto Internacional de Planeamiento de la Educación de la Organización de las Naciones Unidas para la Educación, la Ciencia y la Cultura distingue diversos tipos de universidades virtuales: las recién creadas sobre la base de un modelo de campus completamente virtual y las que se apoyan en un consorcio de asociados que tiene por objetivo fomentar una enseñanza a distancia; $\mathrm{y}$, por último, las empresas comerciales especializadas en servicios educativos que suelen realizar actividades en el campo de la educación a distancia. (UNESCO, 2005, p. 236).
La experiencia ha demostrado que las universidades cuentan con la capacidad y están en condiciones de explotar al máximo las nuevas tecnologías; sin embargo, las inversiones financieras en campus virtuales siguen siendo muy costosas.

\section{La educación que se necesita}

La Educación en México y en el mundo se caracteriza por estar en constante movimiento. No es posible concebir la permanencia de un modelo educativo que perdure. De ahí que se complejice el estudio del modelo de educación acorde a las necesidades del contexto, ya que por su naturaleza cambiante, cuando se siguen discutiendo los efectos y diagnosticando la utilidad del mismo, ya no es vigente.

Lo que no es cuestionable, sino por el contrario resulta de sumo beneficio, es realizar análisis de los modelos para fundamentar y mantener formas de organización que han persistido con el paso de los años, dada su utilidad e incluso fomentar aquellas prácticas que permitan concretar los objetos y fines de la Universidad, en el caso de la Educación Superior o terciaria.

Este artículo se elaboró a partir del análisis y reflexión sobre el contexto actual y la demanda social que recae en los hombros de la universidad partiendo del supuesto en que por sí misma que no puede ejercer sus funciones sin tomar en cuenta la perspectiva y demandas de la sociedad. En el contenido del mismo encontrará una fuerte crítica al reclamo de Newman en 1976 (como se citó en Barnett, 2002) cuando testifica que el conocimiento ya no es un fin en sí mismo.

Esta afirmación se soporta en el hecho de que el “...cuasi - mercado ha reducido aún más la autonomía disfrutada por las universidades como instituciones, y la llegada de la nueva gestión pública" (Barnett, 2002, p.29). Si bien el conocimiento debe ser aplicado para que adquiera un sentido, no puede ser concebido como un valor sujeto a comercializarse o mercantilizarse. Al respecto Lyotard, 1984 (como se citó en Barnett,2002) muestra su tesis denominada "performatividad" afirmando que el conocimiento visto como producto, sabotea los valores de verdad, cambiándolos desde el desinterés al uso pragmático y al valor de cambio. 
Esta nueva perspectiva, y bajo esta premisa en donde el conocimiento ha de tener un valor susceptible a ser comercializado, Barnett (2002) reafirma que "el conocimiento ya no puede ser su propio fin, sino que ha de tener un valor de uso, que sea percibido como tal por el usuario" (p.33) y él mismo se ha convertido en un producto al haber incorporado a la Universidad el modelo de gestión empresarial, desvirtuando su espíritu desinteresado y cooperativo, donde la eliminación de fronteras han dado pie a una Universidad denominada posmoderna en la que la transferencia del conocimiento no tiene límites.

En este punto del análisis reflexivo en función de la educación que el país y la sociedad necesita, se deben establecer valores de intercambio, donde prevalezca el bien común por encima de intereses monetarios $y$ mercantiles, solo así se podrá frenar la mercantilización que se le ha dado a la educación, pero en especial, a la producción y manejo del conocimiento.

Regresando a Barnett y la idea de presenciar una universidad en disolución, una universidad atenuada donde no se tienen fronteras ni un orden moral evidente. Al respecto el autor indica que la propia disolución de la universidad es una lectura de posmodernidad, en donde el término "universidad", resulta ser inapropiado ya que la misma no puede abarcar los procesos de conocimiento que se desarrollan bajo su nombre.

Esta afirmación no es más que una idea que planea la posibilidad de reorientar el espíritu de la universidad y no sólo como concentradora o generadora del conocimiento a merced de intereses de orden gubernamental y empresarial, a nivel local, nacional o internacional:

“...y y no podemos seguir entendiendo la universidad en término de la categoría de Conocimiento, sino más bien en términos de procesos de cambio y proliferación y dominios del saber; lo que sugiere que, después de todo, podemos aferrarnos a la categoría de conocimiento; sólo tenemos que ser un poco más sutiles al respecto." (Barnett, 2002, p.39)

Partiendo de los supuestos anteriores, no se comparte el concepto de Universidad atenuada $o$ a punto de extinguirse.
Desde el punto de vista de los autores es justo ahora, en este era donde la tecnología acerca y propicia nuevas formas de convivencia, donde la universidad debe prevalecer como aquel recinto donde se generan las ideas, donde se encuentran soluciones a los problemas locales $\mathrm{y}$ donde pueden realizarse aportaciones en beneficio del colectivo; constituye un área de oportunidad para la universidad misma.

No se apoya un debate donde se polarice el capital económico con el capital intelectual cuando ambos pueden encontrar armoniosas coincidencias. Así como universidad y sociedad no pueden verse la una sin la otra, el conocimiento necesita recursos que la empresa puede proveer y la sociedad resulte beneficiada, lo que se deben encontrar son códigos de conducta y valores que permitan desarrollar las actividades de manera autónoma y sin perder de vista el fin de la universidad pública.

Sobre el asunto, Barnett (2002) asegura que en la posmodernidad no hay disponibles valores universales y que la universidad configura los propios en función de los mercados, por lo que se debe soportar en aquellos que provean y garanticen legitimidad y cooperación en esta era global, de manera tal que se beneficien todos.

Con esta reflexión surge la interrogante al dilucidar ¿Cuál es el fin de la universidad pública en la era de la posmodernidad, que acerque el nivel de educación que necesita y se rescate el desarrollo humano? Invariablemente aquel que contemple generar mejores condiciones de vida y resolver la problemática local desde una perspectiva de inclusión donde nadie se quede fuera.

Una universidad que genere y difunda el conocimiento, que forme profesionistas sensibles a la problemática social, una universidad en expansión que adopte un sentido de responsabilidad y contribuya a disminuir las grandes diferencias y desigualdades sociales a través de la inclusión e involucramiento en un entorno que por naturaleza es dinámico y cambiante. 


\section{Referencias}

Apaza Sembinelli, María Fernanda (2007), Configuraciones y características actuales de la Universidad en relación a los Modelos Tradicionales. I Jornadas Nacionales de Investigación Educativa Recuperado el 26 de abril de 2018 de: http://www.feeye.uncu.edu.ar/web/posjornadasi nve/area1/Politicas $\% 20 \mathrm{de} \% 20$ educacion $\% 20 \mathrm{de}$ $\% 20$ evaluacion $\% 20 \mathrm{y} \% 20$ evaluacion $\% 20 \mathrm{de} \% 20$ la\%20politica/221\%20-\%20Apaza\%20$\%$ 20FEEyE.pdf

Approach Moncada, Jesús Salvador (2008). La Universidad: un acercamiento históricofilosófico The University: A HistoricalPhilosophical. Universidad La Salle, México D. F.

Arredondo, D. (2011). Los modelos clásicos de la Universidad Pública. Revista Electrónica de Pedagogía, 15, 1-2. Recuperado de https://www.odiseo.com.mx/articulos/modelosclasicos-universidad-publica

Asociación de Academias de la Lengua Española. (2017). Diccionario de la Lengua Española [versión electrónica]. Madrid, España. Recuperado de: http://dle.rae.es/?id=PTk5Wk1

Barnett,R.(2002). Claves para entender la universidad. España: Ediciones Pomares.

Castells, M. (1996). La era de la información. Economía, Sociedad y Cultura. Vol.1 La Sociedad Red.. Madrid, Allianza Editorial.

Cossio Moreno John Alexander (2018), Tradiciones o culturas pedagógicas: del contexto europeo y norteamericano al conocimiento pedagógico latinoamericano, Volumen 18, Número 1 Enero-Abril pp. 1-23 Este número se publica el $1^{\circ}$ de enero de 2018 DOI: https://doi.org/10.15517/aie.v18i1.31843

Covían, F. (2015). "Las tres raíces de la universidad norteamericana", Revista Cuenta y Razón, 34.

Didriksson,A. (2007). La Universidad en las Sociedades del Conocimiento. Organización de las Naciones Unidas para la Educación, la Ciencia y la Cultura. México, D.F.
Espejo, M., y Martínez, M. (2001). El modelo educativo alemán. Modelo, Características y Descripción. Anales de Política Educativa. España: PoliEduca. Recuperado de: http://www.uco.es/ ed1alcaj/polieduca/dmpe/a nales_voll.htm

Gómez, G. (2013). La universidad a través del tiempo. México: Universidad Iberoamericana.

Ibarrola, María (1986) La Educación Superior en México, CRESALC-UNESCO, ISBN: 9804048-13, recuperado el 28 de abril de 2018 de

http://unesdoc.unesco.org/images/0007/000718/ 071862so.pdf

Krüger,K. (2006) El concepto sociedad del conocimiento. Revista Bibliográfica de Geográfia y Ciencias Sociales, 11(186), pp-pp. Recuperado de http://www.ub.edu/geocrit/b3w683.htm

Marsiske, Renate (2006) La universidad de México: Historia y Desarrollo. Revista Historia de la Educación Latinoamericana, vol. 8, Universidad Pedagógica y Tecnológica de Colombia, Boyacá, Colombia

Medina C., L. y Dora Espinoza (2002) El modelo de innovación curricular en la UAEM: Una aproximación. Segundo congreso nacional y tercero internacional "Retos y expectativas de la universidad". UAEM, 6 al 9 de noviembre. Toluca, Estado de México.

Méndez, R.M. (2017). Las actitudes de los estudiantes hacia la universidad como indicador de calidad, Madrid: Universidad Santiago de Compostela.

Miranda, García David et al. (2005), Modelo de Formación Profesional de la UAEM, Universidad Autónoma del Estado de México, Toluca.

Mureddu, C. (1995). Educación y Universidad. Recuperado de: https://biblioteca.itam.mx/estudios/estudio/letra s39-40/texto04/sec_1.html

Real Academia Española, consulta en línea el 13 de abril, disponible en: http://dle.rae.es/?id=b6TOjV2 
Relancio, Alberto. (2007). Las Universidades Medievales, Ciencia y cultura en la edad media, actas VIII y X, Canarias. ISBN: 84-8309-048

Schriewer, J., \& Keiner, E. (1997). Pautas de comunicación y tradiciones intelectuales en las ciencias de la educación: Francia y Alemania. Revista Mexicana de Investigación Educativa, 2 (3)

Tamez, R y Martínez, F. (2012). Las Reformas que necesita la Educación Mexicana. Edición No venal México.

UNESCO, (2005) Hacia las sociedades del conocimiento, Publicado en 2005 por la Organización de las Naciones Unidas para la Educación, la Ciencia y la Cultura. Disponible en: http//www.unesco.org/publications

Velásquez Giraldo Rodrigo, Morales Gómez Jairo. Historia y Preeminencia de la Universidad Occidental,. Recuperado el 14/04/2018. Disponible en: http://www.unilibre.edu.co/revistaingeniolibre/r evista10/articulos/historia-y-preeminencia-dela-universidad-occidental.pdf 